\title{
A RANDOMIZED CLINICAL TRIAL COMPARING EFFICACY OF VITRECTOMY WITH INTRA VITREAL TRIAMCINOLONE ACETONIDE INJECTION AND SIMPLE VITRECTOMY IN PATIENTS WITH VITREOUS HAEMORRHAGE DUE TO PROLIFERATIVE DIABETIC RETINOPATHY
}

\author{
P. Rajeevan ${ }^{1}$, K. Mahadevan².
}

1. Associate Professor, Department of Ophthalmology,Regional Institute of Ophthalmology,Govt Eye Hospital .Trivandrum, Kerala.

2. Professor, Department of Ophthalmology (Retired) Regional Institute of Ophthalmology, TVPM.

\section{CORRESPONDING AUTHOR:}

Dr. P. Rajeevan,

Associate Professor,

RIO, Trivendrum-35.

E-mail: rajeevpalpoo@gmail.com

INTRODUCTION: Proliferative diabetic retinopathy affects about 5-10\%of the diabetic population. It is the advanced form of the disease due to ischemic changes and this indicates progression towards more devastating form ie; end stage diabetic eye disease leading to total blindness. The conventional treatment of this disease has been with laser photocoagulation of the ischemic areas. Serious vision threatening complications of diabetic retinopathy (Advanced Diabetic Eye Disease [ADED]) occur in patients who have not had laser therapy or in whom laser therapy has been unsuccessful. In these groups of patients the treatment is vitrectomy with varying results in regaining and maintaining the regained vision. So Intra Vitreal triamcinolone Acetonide [IVTA] injection has been tried in many centres, because of its anti inflammatory, anti angiogenic, cell migration inhibition properties. In this context to study the efficacy of intravitreal triamcinolone against simple vitrectomy was considered. The comparison of two modes of therapy is best done by a Randomized Controlled Trial. Such studies are not reported from elsewhere in India. Hence this study.

RESEARCH QUESTION: Does Vitrectomy with intravitreal triamcinolone acetonide, improve post vitrectomy visual function in patients with proliferative diabetic retinopathy better than simple Vitrectomy?

DESIGN: Randomized Clinical Trial

SETTING: Tertiary care setting - Regional institute of Ophthalmology, Government Ophthalmic Hospital, Medical College Trivandrum

\section{INCLUSION CRITERIA:}

a) Patients with vision at least perception of light with accurate projection. [Able to perceive light from all quadrants of retina]

b) Medically fit for surgery.

c) Controlled glycemic state as per Glycosylated haemoglobin level.

d) Patients who are willing to participate in the study. 


\section{ORIGINAL ARTICLE}

\section{EXCLUSION CRITERIA:}

a) Patients with vision No Perception of light.

b) Patients with ocular co-morbidity like glaucoma, uveitis.

c) Patients with history of previous eye surgery other than cataract surgery

d) Patients who are not willing to participate in the study

METHODOLOGY: 80 patients have been recruited for the study. One patient withdrew from the study, right at beginning. 79 patients have been randomized into 2 groups- Randomization done using random number tables. Demographic variables collected using standardized questionnaire. Baseline evaluation done including laboratory tests for glycemic control. One group has been subjected to vitrectomy with IVTA and other group subjected to simple vitrectomy. Both groups were followed for 8 weeks. 40 patients of group 1 and 39 patients of group2completed the trial.

OUTCOME VARIABLES: Best corrected visual acuity [BCVA] for distance, measured using standard Snellens distance vision chart, done by 2 Para medical ophthalmic assistants independently and tested for inter observer agreement.

Intra ocular pressure measurements done using Non Contact Tonometer [Topcon] an electronic apparatus which is validated with Goldman applanation tonometer as gold standard. This instrument take 3 readings of intra ocular pressure and computer calculate the mean, we get the mean IOP in mm Hg. The system calibration checked on every Monday. The Lens status of the patients observed with slit lamp biomicroscope and noted as lens opacity stage 1 or stage 2 as per guidelines of the Lens opacity classification system 59

ANALYSIS: Done using SPSS (11th version)

RESULTS: Best Corrected Visual Acuity (BCVA) improved in both the groups.

Marginal improvement in BCVA in the intravitreal triamcinolone treated group is 3/60

There was increase in intra ocular pressure in both the groups.

Even though the mean difference in IOP was statistically significant, it was not clinically significant that warrants anti-glaucoma medication.

The lens opacity in the phakic patients progressed from stage 1 to stage 2 in both the groups post operatively. It was not statistically significant to say that IVTA worsens cataract

\section{CONCLUSIONS:}

1. Best Corrected Visual Acuity [BCVA] improved following surgery in two groups

2. The standard treatment group regained BCVA from baseline of PL+to3/60

3. IVTA group regained BCVA from baseline of PL+to6/60

4. There was no clinically significant increase in intraocular pressure in the post surgical period attributable to IVTA.

5. There was no statistically significant change in the lens status of phakic patients.

6. IVTA in a dose of $0.1 \mathrm{ml}$ [ie; $4 \mathrm{mgm}$ ] is safe.

7. As far as patients are concerned, an improvement of distant vision of $3 / 60$ is useful.

8. The beneficial effect found out in this study is only with a short term follow up of 8 weeks. 


\section{ORIGINAL ARTICLE}

9. Longer duration of follow up with larger sample size is necessary to derive conclusive evidences of the therapeutic effect.

POLICY IMPLICATIONS: The Intra Vitreal injection of Triamcinolone Acetonide should be given to all patients undergoing vitrectomy for advanced diabetic eye disease, since it has definite therapeutic efficacy in improving vision and maintaining the improved vision.

BACKGROUND: Diabetes mellitus is one of the few diseases, which ravage every system of human body. Its stealthy onset and existence is such that one may realize its presence only after the disease has been present for years. It is not surprising that the eye is involved frequently and the commonest and by far the most significant involvement is diabetic retinopathy. ${ }^{1}$

Diabetes mellitus, the most common endocrine disease, is characterized by metabolic abnormalities and by long-term complications involving the eyes, kidney, the nerves and blood vessels. 2

All over the world, diabetes is still with associated complications, for one of the main cause of impairment of vision in adult population. The incidence of diabetic retinopathy in sufferers of diabetes depends upon several factors, the most important being the age of onset of diabetes, the length of its duration, and the control of glycemia and above all the diligence of the observer in searching for early lesion. Until the introduction of insulin, many diabetics died before the occurrence of retinopathy, while there after they continued to live. Owing to their steadily growing survival rate, the frequency of diabetic retinopathy is thus increasing. 3

Burden of illness-globally 135 million diabetics are there.6 this number is likely to increase to 345 million by the year 2025.The prevalence of diabetes in India is $34 \%$ and in Kerala it is $17 \%$ in urban population and $7.5 \%$ in rural8. After 20 years of duration, evidence of Diabetic retinopathy is present in all patients with type 1 diabetes, \& in $80 \%$ of patients with type 2 diabetes. Proliferative diabetic retinopathy affects about $5-10 \%$ of the diabetic population7.

RATIONALE: The conventional treatment of this disease has been with laser photocoagulation of the ischemic areas. Serious vision threatening complications of diabetic retinopathy (Advanced Diabetic Eye Disease [ADED]) occur in patients who have not had laser therapy or in whom laser therapy has been unsuccessful. In these groups of patients the treatment is vitrectomy with varying results in regaining and maintaining the regained vision. So Intra Vitreal triamcinolone Acetonide [IVTA] injection has been tried in many centres, because of its anti inflammatory, anti angiogenic, cell migration inhibition properties. In this context to study the efficacy of intravitreal triamcinolone against simple vitrectomy was considered. The comparison of two modes of therapy is best done by a Randomized Controlled Trial. Such studies are not reported from elsewhere in India. Hence this study.

AIM OF THE STUDY: To study the efficacy of intravitreal triamcinolone injection in visual function in patients with proliferative diabetic retinopathy with high risk characteristics.

\section{OBJECTIVES:}


PRIMARY: To study the effectiveness of Vitrectomy with intravitreal injection of triamcinolone acetonide and to compare the results with that of simple vitrectomy in visual function among patients with vitreous haemorrhage due to proliferative diabetic retinopathy.

SECONDARY: 1. To study whether IVTA injection leads to rise in intra ocular pressure.

2. To study whether IVTA worsens cataract

THE STUDY DESIGN: Randomized clinical trial.

THE SETTING: Tertiary care setting

The Regional Institute of Ophthalmology, Government ophthalmic hospital medical college, Trivandrum. The ophthalmology department is the referral centre for patients with eye diseases coming form the southern districts of Kerala like Trivandrum, Kollam, Alappuzha, and Pathanamthitta and also from Kanyakumari district of the neighboring state of Tamilnadu.

\section{SUBJECT SELECTION:}

INCLUSION CRITERIA: All patients in the age group of 35-70years coming to R.I.O. outpatient department with complaints of defective vision and history of diabetes mellitus after base line evaluation found to suffer from diabetic retinopathy is referred to retina clinic of the institute. After registering there they are fully evaluated for the retinal condition and those patients met the following criteria are included in the study

a. Patients with vision at least perception of light with accurate projection ie; patients who are able to perceive light in all 4 quadrants of retina

b. Medically fit for surgery.

c. Controlled glycemic state -Glycosylated haemoglobin estimated at the time of registration in the retina clinic.

d. Patients who are willing to participate in the study

\section{EXCLUSION CRITERIA:}

a) Patients with vision no Perception of light

b) Patients with ocular co-morbidity like glaucoma, uveitis.

c) Patients with history of previous eye surgery other than cataract surgery

d) Patients who are not willing to participate in the study

ETHICAL ISSUES: The study protocol was approved by human ethical committee of Medical College, Thiruvananthapuram. (Vide appendix Sample size calculation25

As per available information from literature, a mean increase in visual acuity of $30 \%$ from pre operative vision is assumed. Being a trial using intravitreal triamcinolone injection for a follow up of eight weeks it was decided to keep the clinically meaningful effect as an improvement of 30\% from the preoperative vision for an Alfa of 0.05 and a Beta of 0.20 , giving a power of $80 \%$ for the trial. The major outcome being an ordinal variable, sample size calculation done using the formula 


$$
n=p 1(1-p 1)+p 2(1-p 2) * f(\alpha, \beta)
$$

$$
(\mathrm{p} 2-\mathrm{p} 1) 2
$$

$\mathrm{n}=$ number of patients needed in one arm, $\mathrm{p} 1=30 \%, \mathrm{p} 2=60 \%$

$\mathrm{p} 1=$ proportion of vision improvement in standard therapy group.

p2= proportion of vision improvement in intervention group,

$$
\begin{aligned}
& @=5 \%, \beta=20 \% \quad \mathrm{~F}(\alpha, \beta)=[\text { function of } \alpha=7.9] \\
& \mathrm{n}=30(100-30)+60(100-60) * 7.9 \quad \mathrm{n}=(30 * 70)+(60 * 40) * 7.9
\end{aligned}
$$

$(60-30) 2$

$(30) 2$

$\mathrm{n}=(2100+2400) * 7.9=38$

900

Using the above formula it is seen that to detect a difference of $30 \%$ with a power of $80 \%$, the number of patients required in each arm is around 38.During the course of any clinical trial, some participants may not adhere to the prescribed schedule ie: the drop outs .Anticipated drop out $=5 \%$. I have recruited 80 patients for the study

\section{METHOD OF ALLOCATION: RANDOMIZATION:}

The patients with complaints of defective vision and who are diagnosed to have diabetes mellitus attending the retina clinic of regional institute of ophthalmology are evaluated for retinopathy. Those who are found eligible are included in the clinical trial.

a) These patients and their relatives are fully informed about the disease, its management and the purpose of this study verbally and obtained a written consent in local language Malayalam. They were randomized into two groups by simple randomization procedure using random number tables (vide appendix) using sealed envelopes. Two digit numbers up to 90 were used. Those falling, below 45, being allotted to group 1, and those above 45 to group 2. Numbers above 90 and 00 were ignored

b) The primary outcome is Best Corrected Visual Acuity. The measurement scale used is the standard Snellens distant vision chart. It is an ordinal variable and measurement is subjective. In order to avoid possible measurement bias, Measurement of best corrected visual acuity was done by 2 Para medical ophthalmic assistants' one working in the refraction unit of outpatient department and the other in the retina clinic who were masked about type of intervention each patient underwent. The BCVA of the first 20 patients were measured by 2 PMOAS independently. The inter observer agreement tested by kappa statistics, which showed good agreement. So the rest of the patients BCVA measured by one PMOA only.

c) INTER OBSERVER AGREEMENT 


\section{ORIGINAL ARTICLE}

Observed

Observer - 1

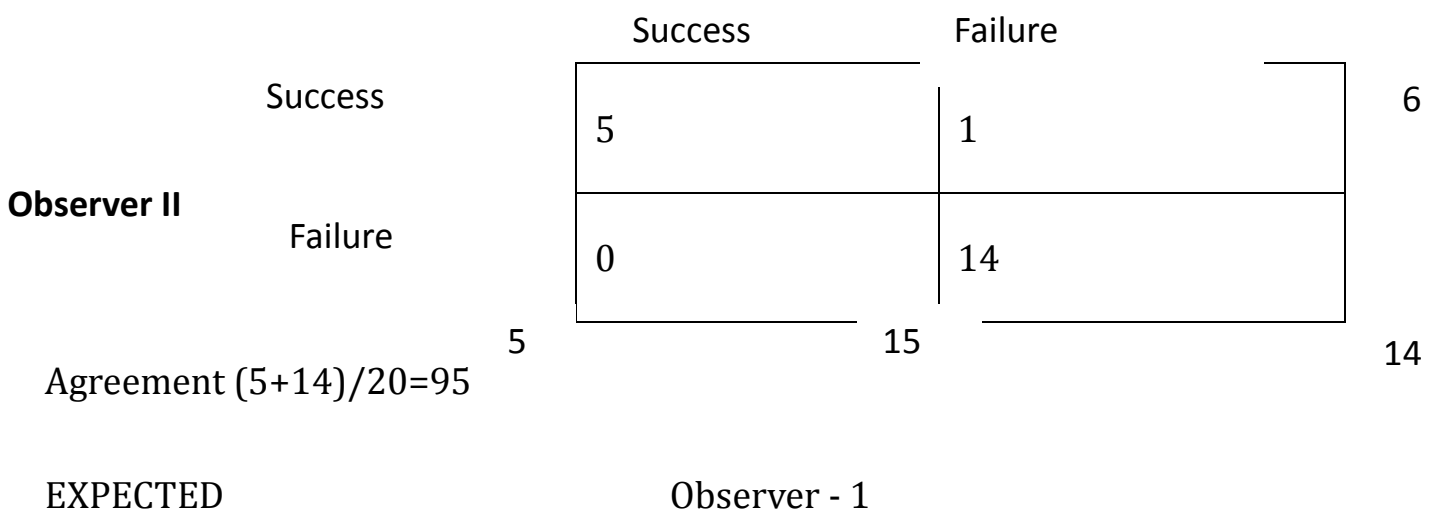

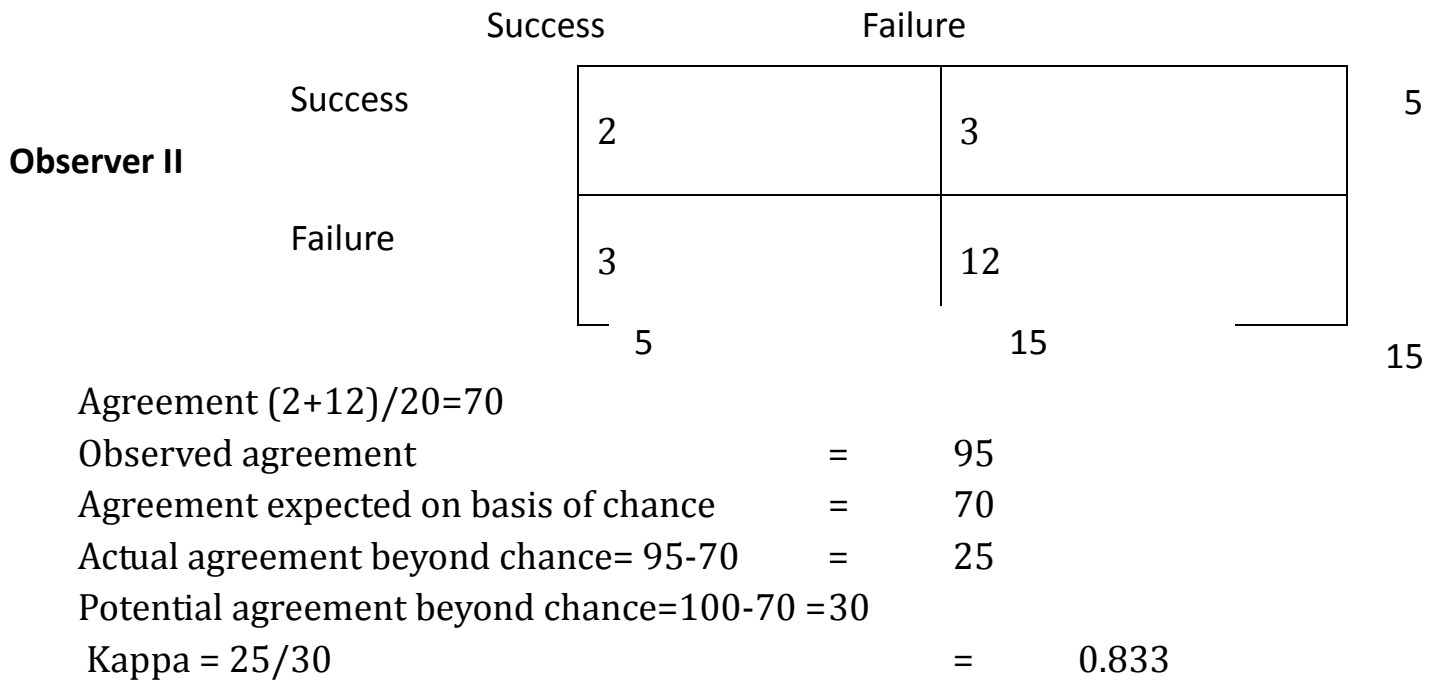

THE PROCEDURE: The baseline data regarding demographic variables of each patient was taken using a standardized questionnaire, (vide appendix). The correct postal addresses were noted carefully in all cases.

The standard procedure: which is being followed in our hospital, ie simple vitrectomy is done for Group 2- patients.

The test procedure: Vitrectomy, with intravitreal triamcinolone acetonide $(0.1 \mathrm{ml}$ ie: $4 \mathrm{mg})$.is done for group1 patients.

All patients were operated by same surgeon

There is no co intervention

OUTCOME MEASURES: The primary outcome is Best Corrected Visual Acuity. The measurement scale used is the standard Snellens distant vision chart. It is an ordinal variable and measurement is subjective. In order to avoid possible measurement bias, Measurement of best corrected visual acuity was done by 2 Para medical ophthalmic assistants' one working in the refraction unit of outpatient department and the other in the retina clinic who were masked about type of intervention 
each patient underwent. The BCVA of the first 20 patients were measured by 2 PMOAS independently. The inter observer agreement tested by kappa statistics, which showed good agreement. So the rest of the patients BCVA measured by one PMOA only.

Secondary outcomes-1 Intraocular pressure, 2.lens changes, 3.other adverse events, like rebleeding, retinal detachment.

First Post Operation visit - done on the next day morning.

The condition of the operated eye examined, using slit lamp bio microscope Intra Ocular Pressure measured using non-contact tonometer. This is a digitalized instrument validated with Goldman applanation tonometer as the gold standard.

Patients got discharged with advise to use topical antibiotic steroid combination chloramphenicol $1.0 \% \mathrm{w} / \mathrm{v}$ with dexamethasone $(0.1 \% \mathrm{w} / \mathrm{v}) 2$ drops four times a day, and Atropine sulphate $1 \%$ topical solution once at night and to continue all the medications they were using for their systemic illnesses including diabetes, All the patients were called for follow up regularly on first week, fourth week, and eighth week. During every visit anterior segment examination with slit lamp, intraocular pressure measurement using non-contact tonometer and Fundus examination by indirect ophthalmoscopy was done.

Clinical Trial Flow Diagram

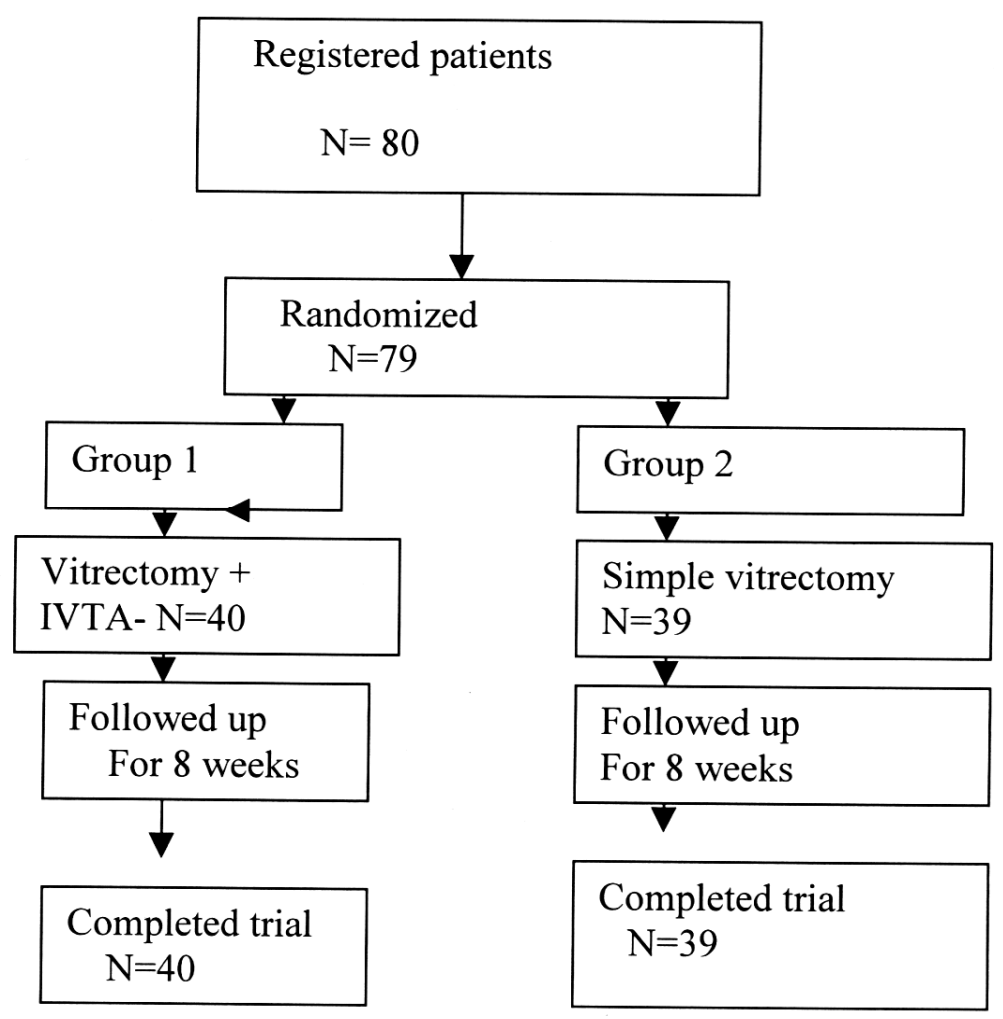


RESULTS AND ANALYSIS: The patients having gross defective vision due to proliferative diabetic retinopathy with high risk characteristics ie: vitreous haemorrhage, attending the retina clinic of Regional Institute of Ophthalmology, Trivandrum were recruited for the study. The where divided into 2 groups using the simple randomization procedure. One group was subjected to vitrectomy with intravitreal triamcinolone injection and the other group was subjected to simple vitrectomy with saline replacement. The patients were followed up for 8 weeks and the data analysis was done at the end of that period.

The analysis was done by a statistical expert using SPSS statistical package 11 nth version.

OUTCOME MEASURES: THE PRIMARY OUTCOME: measured in this study is improvement of visual acuity. This is done with the standard Snellens distant vision chart which is being widely used for the purpose. This is an ordinal variable. The measured visual acuity of the study subjects given grades from 0 to 7 [only PL+=0; PL+t01/60=1; >1/60-2/60=2; >2/60-3/60=3; >3/60-6/60=4; $>6 / 60-6 / 36=5 ;>6 / 366 / 24=6 ;>6 / 24=7]$. This measurement being subjective in order to eliminate bias 2 PMOA s measured the vision in the post surgical period and tested for inter observer agreement by kappa statistics which showed good agreement.

\section{THE SECONDARY OUTCOMES:}

1. The intra ocular pressure measured in $\mathrm{mm}$ of hg with non contact tonometer. The measurement is taken using validated digital NCT. So possibility of bias is eliminated

2. The lens changes noted in the subjects during the study period using slit lamp bio microscope. This is given grades-from 1to2. [1=LOCS1; 2=LOCS2]

3. The posterior segment findings noted using indirect ophthalmoscope. This is categorized into 5 types 5 -[1=residual blood+; 2 =fibrous bands+; 3 =re bleeding+; 4=retinal detachment+; $5=$ residual blood and fibrous bands +$]$

\section{STATISTICAL METHODS USED:}

The improvement in distant vision being an ordinal variable, Variability is tested using Nonparametric test- Mann Whitney U- test.

The difference in IOP being a continuous variable independent sample t test is used for comparing the variability.

The changes in the lens status of phakic patients participated in the study being qualitative chi square test is used for testing the variability.

The fundus picture observed with indirect ophthalmoscope being a qualitative variable chisquare test is used testing variability.

The baseline characteristics of the two groups are presented in the following pages

\section{1) AGE}

The age distribution of the two groups are shown in the table 


\section{ORIGINAL ARTICLE}

TABLE - 1

\begin{tabular}{|l|l|l|}
\hline Type of treatment & & Age of patients \\
\hline Standard treatment & Number 39 & \\
\hline & Mean & 55.90 \\
\hline & Median & 55.00 \\
\hline IVTA & Std. Deviation & 9.011 \\
\hline & Number 40 & \\
\hline & Mean & 54.28 \\
\hline & Median & 56.00 \\
\hline & Std Deviation & 7.565 \\
\hline
\end{tabular}

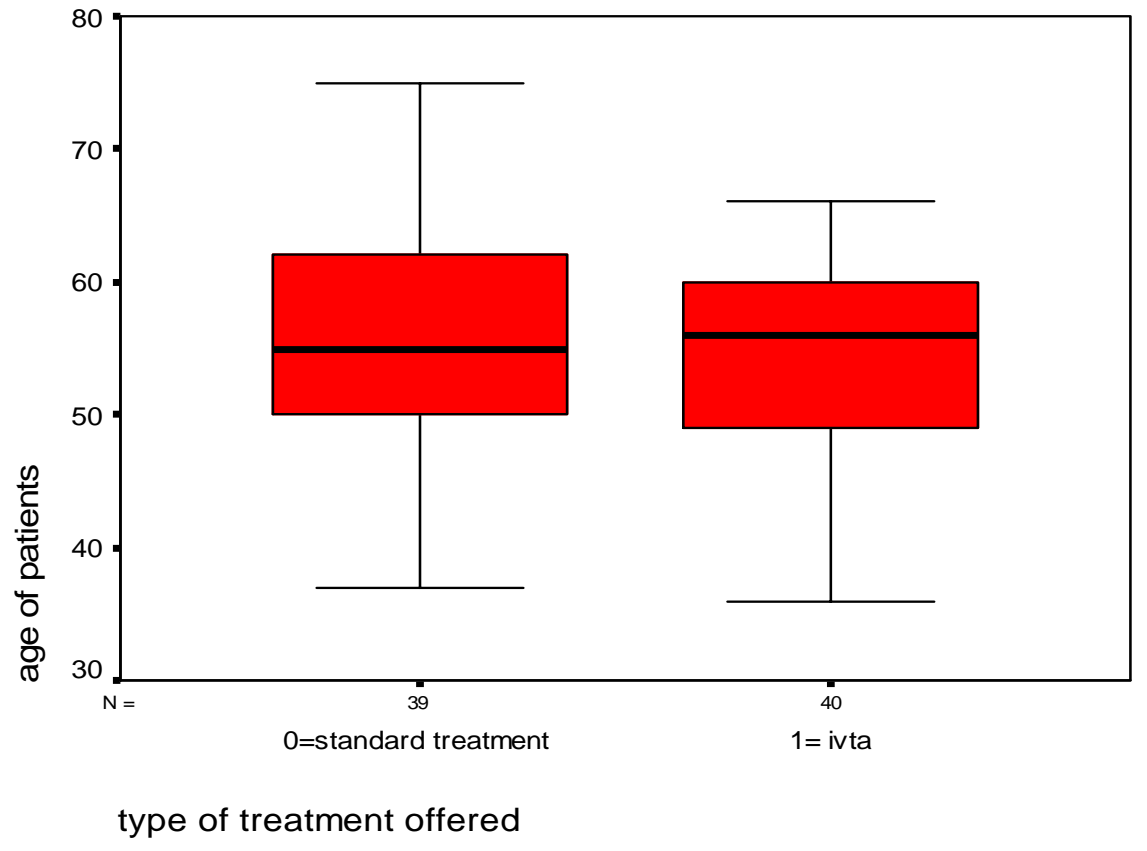

It is seen that median age is 55yrs in standard $\mathrm{r} / \mathrm{x}$ group \&56yrs in ivta group. It is comparable in both the groups. 


\section{ORIGINAL ARTICLE}

\section{2) GENDER OF PATIENTS:}

TABLE-2

\begin{tabular}{|l|l|l|l|}
\hline Type of treatment & Gender & Frequency & Valid percent \\
\hline Standard treatment & Male & 22 & 56.4 \\
\hline & Female & 17 & 43.6 \\
\hline IVTA & Male & 21 & 52.5 \\
\hline & Female & 19 & 47.5 \\
\hline
\end{tabular}

In group 1 there are 22 males and 17 females whereas in goup2 there are 21 males and 19 females. Comparable in both the groups

Gender of patients

TYPEOFRX:=standard treatment

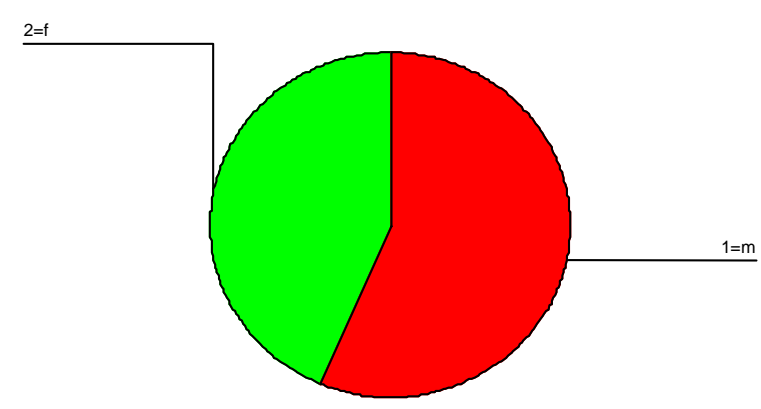

Gender of patients

TYPEOFRX: : ivta

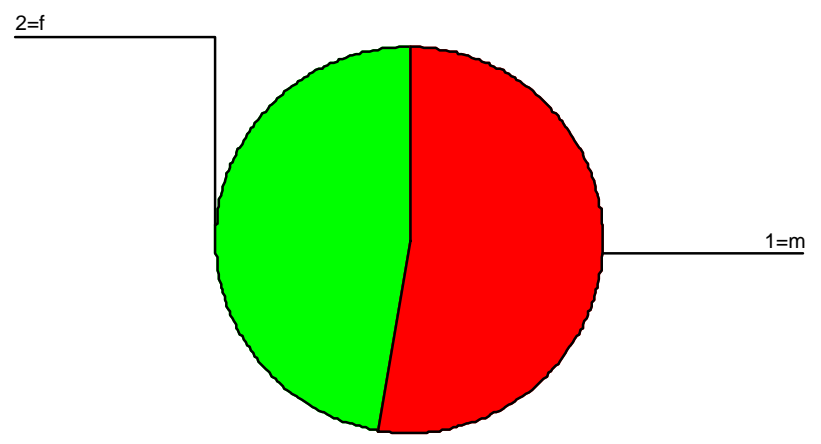




\section{3) OCCUPATION OF PATIENTS}

TABLE - 3

The occupational status was divided into 5 categories

1. Office going, 2. Self employed.

3. Skilled labourer $\quad$ 4. Unskilled labourer $\quad 5$. Household jobs

\begin{tabular}{|l|l|l|l|}
\hline Type of treatment & & Frequency & Valid Percent \\
\hline Standard treatment & Office going & 2 & 5.1 \\
\hline & Self employed & 9 & 23 \\
\hline & Skilled & 5 & 12.8 \\
\hline & Semi Skilled & 7 & 17.9 \\
\hline & House hold jobs & 16 & 41.0 \\
\hline IVTA & Office going & 6 & 15.0 \\
\hline & Self employed & 10 & 25.0 \\
\hline & Skilled & 4 & 10.0 \\
\hline & Semi skilled & 3 & 9.0 \\
\hline & House hold jobs & 17 & 51 \\
\hline
\end{tabular}

It can be seen from the table that majority of patients were having house hold jobs in both the groups.

4) MONTHLY INCOME OF PATIENTS

TABLE - 4

\begin{tabular}{|l|l|l|}
\hline Type of treatment & Monthly income in INR & Frequency \\
\hline Standard treatment & $<500$ & 18 \\
\hline & $500-1000$ & 8 \\
\hline & $1001-1500$ & 9 \\
\hline & $>1500$ & 4 \\
\hline IVTA & $<500$ & 11 \\
\hline & $500-1000$ & 13 \\
\hline & $1001-1500$ & 5 \\
\hline & $>1500$ & 11 \\
\hline
\end{tabular}

Though the monthly income of patients shows an apparent difference it was not found to be statistically significant ( $\mathrm{p}$-value 0.064 ).

5) DURATION OF DIABETES MELLITUS: The distribution of duration of diabetes has an almost identical pattern in both the groups

Analysis show no statistical significant difference between 2 groups (p value->.05)

6) CURRENT TREATMENT TAKEN BY THE PATIENTS: No significant difference between two groups. P value $>0.05$ 
7) OTHER SYSTEMIC ILLNESS -the patients suffering from: Data obtained by history Past medical illness grouped into 9 categories.

It was not found to be statistically significant.

8) SYSTOLIC BLOOD PRESSURE: The systolic blood pressure recorded preoperatively in both group of patients. Independent sample t-test shows no statistical significance

9) DIASTOLIC BLOOD PRESSURE: The diastolic blood pressure recorded pre operatively in both groups of patients. There is no statistical significance ( $p$-value $>0.05$ )

10) GLYCOSYLATED HAEMOGLOBIN - Estimated at the time admission to the ward In 2 group of patients

TABLE - 10

\begin{tabular}{|l|l|l|l|}
\hline \multicolumn{2}{|l|}{} & \multicolumn{2}{l|}{ Hb A1c in gms\% } \\
\hline No :of pts & Type of r/x offered & Mean & S.D \\
& & & \\
\hline 39 & Standard r/x & 5.61 & 0.09 \\
\hline 40 & IVTA & 5.63 & 0.10 \\
\hline
\end{tabular}

Analysis show no significant difference between 2 groups (p-value.865)

\section{1) HISTORY ONSET OF LOSS OF VISION IN 2 GROUPS CATEGORIZED INTO 4}

1. Sudden onset unilateral, $\quad 2$. Gradual onset unilateral, 3. Sudden onset unilateral, 4. Gradual onset bilateral

TABLE - 11

\begin{tabular}{|l|l|l|l|}
\hline H/O loss of vision & Std R/X & ivta & Total \\
\hline Sudden onset U/L & 7 & 13 & 20 \\
\hline Sudden onset B/L & 2 & 0 & 2 \\
\hline Gradual onset U/L & 6 & 1 & 7 \\
\hline Gradual onset B/L & 24 & 26 & 50 \\
\hline TOTAL & 39 & 40 & 79 \\
\hline
\end{tabular}

Analysis shows no statistical difference between 2 groups ( $p$ value $>0.05$ )

\section{2) HISTORY OF PAN RETINAL PHOTOCOAGULATION IN 2 GROUPS OF PATIENTS}

TABLE - 12

\begin{tabular}{|l|l|l|l|}
\hline H/O PRP & Std R/X & IVTA & Total \\
\hline PRP not done & 11 & 14 & 25 \\
\hline PRP done & 28 & 26 & 54 \\
\hline Total & 39 & 40 & 79 \\
\hline
\end{tabular}




\section{ORIGINAL ARTICLE}

Analysis show no statistical difference between 2 groups by fissure exact test ( $\mathrm{p}$ value $>0.05$ )

13) PRE OPERATIVE ANTERIOR SEGMENT FINDINGS IN 2 GROUPS: Preoperative anterior segment findings-lens status by LOCS classification. Findings of, to be operated eye grouped into 3 according to density of lens opacity in increasing grades

$\begin{array}{lll}\text { 1. LOCS1 } & \text { 2. LOCS2 Pseudophakic (already underwent cataract surgery with IOL }\end{array}$ implantation)

TABLE -13

\begin{tabular}{|l|l|l|l|}
\hline Pre op a/s & Std R/X & IVTA & Total \\
\hline LOCS 1 & 8 & 10 & 18 \\
\hline LOCS2 & 10 & 11 & 21 \\
\hline PSEUDOPHAKIA & 21 & 19 & 40 \\
\hline Total & 30 & 40 & 79 \\
\hline
\end{tabular}

Analysis shows no significant statistical difference between 2 groups. (P value $>0.05$ )

\section{4) PRE OPERATIVE VISUAL ACUITY IN THE EYE TO BE OPERATED}

TABLE - 14

\begin{tabular}{|l|l|l|l|}
\hline Pre op V/A & Std R/X & IVTA & Total \\
\hline Only PL+ & 21 & 20 & 41 \\
\hline $1 / 60$ & 16 & 19 & 35 \\
\hline $3 / 60$ & 2 & 1 & 3 \\
\hline Total & 39 & 40 & 79 \\
\hline
\end{tabular}

Analysis show no statistically significant difference the 2 groups ( $\mathrm{p}$ value $>0.05$ )

15) PRE OPERATIVE FUNDUS FINDINGS IN THE TO BE OPERATED EYE- GROUPED INTO 2 CATEGORIES

1. PDR with high risk characteristics-B (Less extensive NVD, associated with vitreous or preretinal haemorrhage)

2. PDR with HRC - C (NVE more than one-half disk area associated with vitreous haemorrhage)

16) PREOPERATIVE IOP NOTED WITH NCT IN THE EYE TO BE OPERATED

TABLE - 16

\begin{tabular}{|l|l|l|l|}
\hline Pre op IOP in mm Hg & STD R/X & IVTA & Total \\
\hline 14 & 2 & 7 & 9 \\
\hline 15 & 13 & 14 & 27 \\
\hline 16 & 12 & 13 & 25 \\
\hline 17 & 12 & 6 & 18 \\
\hline Total & 39 & 40 & 79 \\
\hline
\end{tabular}




\section{ORIGINAL ARTICLE}

Analysis show no statistical significance ( $\mathrm{p}$ value $>0.05$ )

17) INTRA OPERATIVE COMPLICATIONS

TABLE - 17

Analysis show no statistical difference ( $\mathrm{p}$ value->0.05)

\begin{tabular}{|l|l|l|l|}
\hline Complications & STD R/X & IVTA & Total \\
\hline No complications & 30 & 31 & 61 \\
\hline Persistent bleeding & 5 & 7 & 12 \\
\hline Iatrogenic hole >RD & 4 & 2 & 6 \\
\hline TOTAL & 39 & 40 & 79 \\
\hline
\end{tabular}

\section{8) POST OPERATIVE ANT; SEGMENT FINDINGS IN THE OPERATED EYE AT 8 WEEKS}

Noted by slit lamp examination grouped into 3 categories

1. LOCS1 2. LOCS2 3.PSUEDOPHAKIA,

\begin{tabular}{|l|l|l|l|}
\hline Post op a/s findings & Std R/X & IVTA & Total \\
\hline LOCS 2 & 18 & 21 & 39 \\
\hline PSEUDOPHAKIA & 21 & 19 & 40 \\
\hline TOTAL & 39 & 40 & 79 \\
\hline
\end{tabular}

Analysis show no statistical significance between groups fissure exact test ( $\mathrm{P}$-value $>0.05$ ).

19) DIFFERENCE IN THE BEST CORRECTED VISUAL ACUITY FROM BASELINE TO THAT ATTAINED AT END OF 8 WEEEKS

\begin{tabular}{|l|l|l|l|}
\hline D_BCVA at 8weeks & STD R/X & IVTA & Total \\
\hline $1 / 60$ & 1 & 0 & 1 \\
\hline $2 / 60$ & 1 & 0 & 1 \\
\hline $3 / 60$ & 16 & 6 & 22 \\
\hline $6 / 60$ & 19 & 15 & 34 \\
\hline $6 / 36$ & 2 & 15 & 17 \\
\hline $6 / 24$ & 0 & 4 & 4 \\
\hline Total & 39 & 40 & 79 \\
\hline
\end{tabular}

RANKS 


\section{ORIGINAL ARTICLE}

\begin{tabular}{|l|c|l|l|}
\hline Type of R/X offered & $\mathrm{N}$ & Mean Rank & Sum of Ranks \\
\hline Standard R/X & 39 & 29.27 & 1141.50 \\
\hline IVTA & 40 & 50.46 & 2018.50 \\
\hline
\end{tabular}

Test Statistics

\begin{tabular}{|l|l|}
\hline & Difference BCVA at 8 wks. In grades \\
\hline Mann Whitney U & 361.500 \\
\hline Wilcoxon W & 1141.500 \\
\hline $\mathrm{Z}$ & -4.353 \\
\hline Asymp. Sig (2 tailed) & .000 \\
\hline
\end{tabular}

\section{difference in BCVA at 8weeks}

\section{TYPEOFRX: $\quad 0 \quad 0=$ standard treatment}

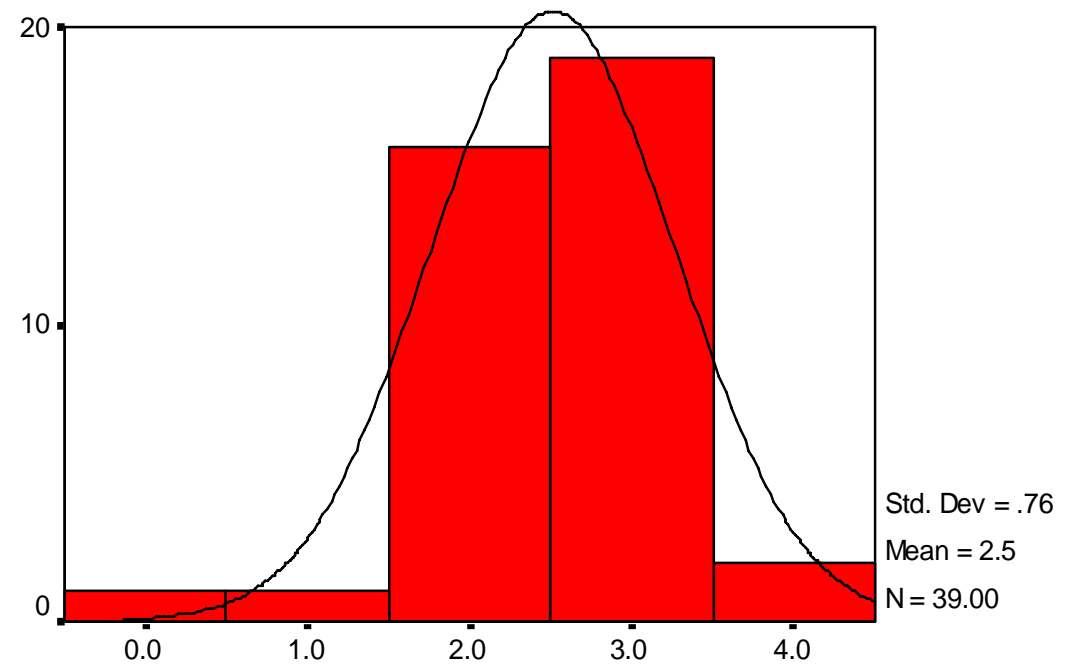

difference bcva at8wks in grades 


\section{ORIGINAL ARTICLE}

20) DIFFERENCE IN INTRAOCULAR PRESSURE FROM BASELINE TO THAT MEASURED AT 8WEEKS BY NCT

TABLE - 20

\begin{tabular}{|l|l|l|}
\hline Type of treatment & Mean d_In IOP in mm Hg & $\begin{array}{l}\text { Standard } \\
\text { deviation }\end{array}$ \\
\hline STDR/X & 0.62 & 0.544 \\
\hline IVTA & 1.08 & 0.97 \\
\hline
\end{tabular}

Analysis shows significant difference between two groups ( $p$ value $<0.01$ )

\section{1) DIFFERENCE IN ANTERIOR SEGMENT FINDINGS FROM BASELINE TO THAT AT 8WEEKS IN THE OPERATED EYE}

TABLE - 21

\begin{tabular}{|l|l|l|}
\hline $\begin{array}{l}\text { Change in ant; seg } \\
\text { findings }\end{array}$ & STD R/X & IVTA \\
\hline LOCS1-> LOCS 2 & 8 & 10 \\
\hline
\end{tabular}

Analysis show no statistically significant difference between 2 groups by Fishers exact (P value $>0.05$ )

\section{2) POST OPERATIVE FUNDUS FINDINGS AT THE END OF 8 WEEKS}

Categorized into 5[1=residual blood +;2=fibrous bands+;3=rebleed+; 4=retinal detachment+; $5=$ residual bleeding and fibrous band + ]

TABLE - 22

\begin{tabular}{|l|l|l|l|}
\hline Post op F findings & $\begin{array}{l}\text { STD R/X } \\
\text { GROUP }\end{array}$ & IVTA & TOTALP \\
\hline Residual blood+ & 14 & 14 & 28 \\
\hline Fibrous bands + & 20 & 24 & 44 \\
\hline Retinal detachment + & 4 & 2 & 6 \\
\hline Residual blood and f & 1 & 0 & 1 \\
Fibrous band+ & & & \\
\hline Total & 39 & 40 & 79 \\
\hline
\end{tabular}

Statistical analysis showed no significant difference between 2 groups ( $\mathrm{p}$ value $>0.05$ ) 


\section{ORIGINAL ARTICLE}

DISCUSSION: Diabetic retinopathy is a chronic illness prevalent in both the developing and developed countries. It progresses to proliferative stage in 4-5\%of diabetics. From this stage it acquires high- risk characteristics, as Vitreous haemorrhage and tractional retinal detachment. In this stage (advanced diabetic eye disease) patients suffer from severe visual loss.26. The high morbidity associated with ADED are linked to the failure to identify at- risk patients and to intervene timely. Early identification requires an awareness of risk factors and proper clinical assessment .Once PDR with high risk characteristics are identified active intervention to slow the progression to end stage diabetic eye disease and blindness is essential to improve the vision and thereby the quality of life. The disease drags on for a number of years leading to loss of productivity and the patient becomes an economic burden to the family and the society.

Randomized clinical trial is the most powerful tool available for the evaluation of true benefits of therapeutic interventions.27. As this was a study comparing the efficacy of two therapeutic interventions, RCT was chosen as the appropriate design.

Vitrectomy have occupied the pride of place as the treatment of choice in proliferative diabetic retinopathy with high risk characteristics ie; vitreous haemorrhage or tractional retinal detachment both in the western countries and in India. Intravitreal injection of triamcinolone acetonide has been proved to be very useful in the management of proliferative diabetic retinopathy.

Triamcinolone has inhibitory effects on angiogenesis and inflammatory reactions by reducing the migration and activation of inflammatory cells. It also inhibits the production of vascular endothelial growth factor. Steroids are also known to stabilise endothelial basement membrane and reduce vascular permeability and leakage through their inhibitory effect on plasmin. Therefore there are theoretical reasons to expect that IVTA could potentially work for a number of retinal conditions characterised by inflammation, vascular leakage, and new blood vessel growth.40

IVTA has been used for many retinal vascular conditions with varying results Since there is no published results of similar studies from India I thought of undertaking this study.

The prevalence of proliferative diabetic retinopathy in the city of Trivandrum in Kerala in population above 35 years is $1 \% 57$.The percentage of patients with retinal diseases coming to the Regional Institute of Ophthalmology, Trivandrum is 20.0ne third of patients referred to the retina clinic is diagnosed to have diabetic retinopathy. Among this 5\%is having PDR with vitreous haemorrhage/ tractional retinal detachment.58

The sample size for this study was calculated to detect an improvement in vision of $100 \%$ in the IVTA group compared to the standard treatment which is being followed in our institute.

Visual recovery following surgery, in the IVTA group, from baseline of PL+ to 6/60. For an alpha of .05 and beta of 20 and adjusting for dropouts of 5\%, the sample size required was found to be 40 patients in each arm.

The patients recruited for the randomized clinical trial were chosen from those with features of proliferative diabetic retinopathy with vitreous haemorrhage (advanced diabetic eye disease) by indirect ophthalmoscopy and B-scan ultrasonography.80 patients were found eligible. Randomization was done after obtaining written informed consent, using random number tables and the patients were divided into 2 groups.

Group 1[intervention group] patients were subjected to vitrectomy, membrane peeling, band segmentation, endo diathermy and IVTA injection $0.1 \mathrm{ml}$ containing $4 \mathrm{mg}$ of suspension of commercially available triamcinolone acetonide. 


\section{ORIGINAL ARTICLE}

Group 2[control group] patients were subjected to vitrectomy, membrane peeling band segmentation and endodiathermy. There was no co-intervention.

In both the groups' vitreous replacement is done with normal saline.

Post operative management was exactly similar in both groups.

The baseline characteristics of the two groups were comparable. Out of the 79 patents $57 \%$ belonged to the age of 55years, as diabetic retinopathy is mainly a problem affecting middle age people. The mean age was 55.9years with S.D of 9.0 in group1and 54.28years with SD of 7.6 in group2.Though there is a slight disparity in the ages, it was not found to be statistically significant.

There were21males and 19 females in group1and 22 males and 17 females in group2.Here also a Fishers exact test was done and the p- value was found to be $>0.05$,

On comparison of the occupation it was seen that17/40 (40.25\%) of group1 and 16/39(41\%) of group2 were having house hold jobs. No statistically significant difference between 2 groups

The economic status of the patients assessed by noting monthly income showed that $11 / 40(27.5 \%)$ in goup1 and $18 / 39(46 \%)$ in group2 belong to poor socio economic status, having income less than Rs. 500/-per month, show that majority of patients attending government hospital belong to the poor socio economic strata. Statistical analysis shows that chi- square value of 7.267 with a p- value.>.0.05) noting no significant difference between 2 groups.

The duration of diabetes mellitus was15-19 years in $13 / 40(32.5 \%)$ ingroup1and16/39(41\%) in-group 2 and more than 20 years in 14/40(35\%) in group 1 and $12 / 39(30 \%)$ in goup2 patients. This shows that proliferative diabetic retinopathy develops in patients with longer duration of diabetes. Analysis show a chi-square value of .618 with a p value of $>0.05(.734)$, indicating no significant difference between 2 groups.

Present treatment taken by the patients for diabetes $-16 / 40(40 \%)$ in group1 and $10 / 39(26 \%)$ were on injection insulin only and 22/40(55\%) in group1 and 29/39(74\%) in group2 were on combination of oral hypoglycaemic agents and insulin

Analysis show a chi-square value of 4.55 with a p- value.0.05 (.115), again indicate no significant difference between 2 groups.

Other systemic illnesses from which the patients were suffering was noted by history taking. It was categorised into 9 items. The major illnesses were hypertension, coronary artery disease, renal disease, neurological diseases and various combinations of these.11/40 (27.5\%)in group1 and 15/39(38.5\%)in group 2 were suffering from HT+CAD+RD.12/40(30\%)in group1 and 9/39(23\%) in group2. this is also comparable in 2 groups. Statistical analysis shows no significance chi square3.782, p value->0.05 (.458.)

The blood pressure measured in the morning of day of surgery. Systolic and diastolic B.P separately tabulated. The mean systolic blood pressure in group 1 patients is $129+/-6.5 \mathrm{mmhg}$, and mean diastolic BP is $85.50+/-4.2 \mathrm{mmhg}$, where as in group 2 patients, corresponding figures are systolic BP 130.36+/-6.3, mm Hg, diastolic BP 86.67+/-4.11 mm Hg .The independent sample t test showed a t- value of 1.223 and $95 \%$ confidence interval $0.71-3.0$ indicating no significant difference between 2 groups (p-value.221)

Glycosylated haemoglobin (HbA1c) estimated at the time of registration. The mean concentration in group 1 patients is $5.61+/-0.58 \mathrm{Gm} \%$, and group 2 patients it is $5.63+/-0.63 \mathrm{Gm} \%$. 
Independent sample $t$ test gave $t$ of .17 , p-value $>0.05$., indicating no significant differences between 2 groups; glycemic state is controlled in 2 groups of patients.

History of onset of loss of vision grouped into 4 categories 1.sudden onset unilateral, 2.gradual onset unilateral, 3.Sudden onset- bilateral, 4.gradual onset bilateral. It was found that $26 / 40(65 \%)$ in group 1 and $24 / 39(61.5 \%)$ in group 2 patients had gradual onset of loss of vision bilaterally, It is comparable in 2 groups chi2 test showed a p value ->0.05 (0.59)

History of undergoing pan retinal photocoagulation for PDR pre operatively, noted in 2 groups since it has an influence on outcome. It was found that $26 / 40(65 \%)$ in group1 and 28/39(71\%) in group2 underwent PRP. Fisher's exact test showed a p-value $>0.05$ (.63), indicating no significant difference between 2 groups.

Evaluation of the anterior segment pre operatively using slit lamp bio microscope giving special emphasis on lens status showed that 19/40(47.5\%) in group1 and 21/39(53.8\%) in group2 underwent cataract surgery pre operatively and posterior chamber IOL in situ in the eye to be operated.11/40(27.5\%) patients in group1 and 10/39(25.6\%) in group 2 patients had grade 2 lens opacity and 10/40(25\%) in group1 and 8/39(20.5\%) in goup2 had grade 1 lens opacity .chi square value .357 . with a $\mathrm{p}$ value $>0.05$ showed the 2 groups were comparable.

Baseline visual acuity for distance in the eye to be operated measured using standard Snellens distant vision chart. In the group1 patients, $20(50 \%)$ had only perception of light, $19(47.5 \%)$ had $1 / 60$, and $1(2.5 \%)$ had $3 / 60$. In group 2 patients $21(53.8 \%)$ had only perception of light, $16(41 \%)$ had $1 / 60$.and $2(5.1 \%)$ had $3 / 60$ Chi-square test showed a $p$ value of $>0.05$ indicating the 2 groups were comparable.

The intra ocular pressure in the eye to be operated recorded using standardized Non contact tonometer on the day before surgery .the figures in group1 the mean IOP was $15.55+/-.95 \mathrm{mmhg}$ and in goup2 it was $15.87+/-.92 \mathrm{mmhg}$ and the $95 \% \mathrm{CI}(-.84-.00$.) indicating the groups were comparable

Fundus findings in the eye to be operated noted using indirect ophthalmoscope in the two groups, divided into 2 categories,

1. PDR with HRC-B, ie; less extensive neo-vascularisation of the optic disc associated with vitreous haemorrhage.

2. PDR with HRC-C ie; neo vascularisation elsewhere in the retina more than one half of the optic disc size associated with vitreous haemorrhage.

It was found that 37/40(92.5\%) in group1 and 39/39(100\%) in group2 had PDR with HRC$\mathrm{C}$ and No significant difference between 2 groups, Fishers exact test showed a p- value $>0.05$.

It can be seen that there was very little inter group variation in the baseline characteristics of randomized patients. Wherever a little discrepancy was noted the appropriate statistical test was done to compare the groups and the test showed variations are of no statistical significance.

Intra operative complications noted in the two groups noted as yes or no. it was found that in group 1-, 31/40(77.5\%) had no complications and 30/39(76.9\%) patients in goup2 had no complications. Major complications were persistent bleeding, iatrogenic holes, and induced retinal detachment. 
World literature shows $25-30 \%$ patients undergoing vitrectomy develop complications intra operatively.5 Our study also found same rate of complications. Analysis shows a p- Value of $>0.05$ (1.0) by Fishers exact test, indicating no significant difference between 2 groups.

The patients were requested to come for follow up at the end of one week, four weeks and at eight weeks. All patients were given the same medicines for topical application in the post operative period. No side effects due to topical medication noted in any of the patients in the two groups.

All the 79 patients participated in the study completed the trial. The various parameters examined were comparable between the groups.

The outcome variables were-

1 , Visual acuity

2. Intra ocular pressure

3. Anterior segment findings with emphasis on lens status

The main outcome variable was best corrected visual acuity (BCVA) for distance, measured at the end of 8weeks.The difference in the BCVA from baseline to that attained at the end of 8weeks calculated in the two groups. The Mann Whitney U test showed a mean rank of 29.27 in the standard treatment group and 50.46 in the IVTA group. $U$ value 361.5 with a 2 tailed significance $p<0.001$.

Anterior segment examination at the end of 8 weeks of follow up done again with slit lamp bio microscope .The finding in the two groups- $21 / 40(52.5 \%)$ in goup1 and 18/39(46.15\%)in group 2 had grade 2 lens opacity. It was further found that 10/40(25\%) in group1, and 8/39(20.5\%) in group 2 who had grade 1 lens opacity in the preoperative period, The progression of lens opacity from pre operative stage to the postoperative period in the phakic patents from grade 1 to grade 2 which can be noted by slit lamp examination, was $11 / 40(27.5 \%)$ and $10 / 39(25.64 \%)$ in goup2 patients, There was no statistically significant difference between 2 groups, (by Fishers exact test $\mathrm{p}$ value $>0.05$ (655.)

During the follow up visits intra ocular pressure measured using non contact tonometer. The difference in IOP recorded from baseline to that at the end of study was calculated.

The mean difference in IOP in the intervention group was $1.08+/-.971(\mathrm{~mm} \mathrm{Hg})$ and in the standard treatment group was $0.62+/-.544$ (mm Hg).Independent sample t-test for equality of means when equal variance assumed was done. This showed a t- value of 2.587 with 77 degrees of freedom, 2 sided significance $<0.05$ (0.012) [95\%C.I (0.106-0.813)]. Mean difference is $0.46 \mathrm{~mm} \mathrm{Hg}$, even though there is a statistical significance the clinically meaningful difference which warrant medication for IOP reduction is 3mmhg or when IOP recorded goes beyond the accepted normal limits (15-21mmhg). None of the patients has been put on anti glaucoma medication during the entire follow up period.

Posterior segment findings observed with indirect ophthalmoscope at the end of 8 weeks .It was found that in the intervention group 14/40(35\%) and in the standard treatment group $14 / 39(35.89 \%)$ had residual bleeding.

In group1 -24/40(60\%) and in group2- 20/39(51.2\%) had fibrous bands.

In group1 2/40(5\%) and in group $24 / 39(10.25 \%)$ had residual bleeding +fibrous bands. Re bleeding was fond only in one patient in the standard treatment group. 


\section{ORIGINAL ARTICLE}

Statistical analysis showed a chi-square -2.018 and p-value $>0.05$. There is no statistically significant difference between 2 groups.

The primary objective of the study was to find out whether intravitreal injection of triamcinolone in patients undergoing vitrectomy for proliferative diabetic retinopathy with vitreous haemorrhage will produce a significant improvement in BCVA from the baseline when compared to simple vitrectomy.

The secondary objectives were1) to find out whether IVTA will lead on to rise intra ocular pressure,2) to find out whether IVTA worsens cataract .

The difference in BCVA from the baseline to the final follow up -in both the groups was compared using Mann Whitney -U test. It was found to be statistically significant.

The difference intra ocular pressure measured using non contact tonometer from baseline to that at 8weeks calculated in both the groups and compared using independent samples t test. Even though it showed a statistically significant difference it is less than clinically significant difference, which warrant anti glaucoma medications.

To find out whether IVTA worsens cataract the lens status in the pre operative period and that at the end of the study in phakic patients in the 2 groups were compared using Fisher's exact test. It showed no statistically significant difference between the two groups to say that IVTA worsens cataract.

The posterior segment findings noted using indirect ophthalmoscope at the end of 8 weeks categorized into 5, compared using chi-square test showed no significant difference between the 2 groups.

Proliferative diabetic retinopathy with vitreous haemorrhage [ADED] is a disease characterised by Severe Visual Loss [SVL]. Active intervention is the key to regain some amount of useful vision.

The Diabetic Retinopathy Vitrectomy Study [DRVS] advocates early surgical intervention in this group of patients.23. There are many studies in the western world to find out the efficacy of IVTA in the treatment of proliferative diabetic retinopathy with clinically significant macular oedema. The main outcome measure that they looked was improvement of BCVA and decline in macular oedema. The follow up period was longer. As the period of follow up in this study was only 8 weeks a short term improvement in BCVA was the one that could be found out. Such short term improvement was noted by Florian K.P. et-al-Vision research group in Florida. Continued follow up of these patients revealed further improvement and stabilisation of improved vision occur after 6 months.24,.25.

As a rule of thumb post surgical improvement of $3 / 60$ from baseline BCVA is regarded as success. This study also shows a difference of [PL+ TO 3/60] in standard treatment group and [ PL+ to 6/60] in the intervention group which show that treatment is effective in both the groups but more effective in the IVTA group.

The main appeal of Randomized Clinical Trials in health care derives from its potential for reducing selection bias. We could keep the study group as similar as possible because of proper randomization enabling us to isolate and quantify the interventions under study. Random allocation does not protect against measurement bias, In order to reduce measurement bias in this study the Para medical ophthalmic assistants measuring the visual acuity was masked about the nature of intervention [IVTA or standard treatment]. 
The clinical trial shows that there is an added benefit in regaining BCVA in the patients treated with IVTA. There was a statistically significant difference between the groups.

The advantages of IVTA during pars plana vitrectomy are delineation of cortical vitreous and internal limiting membrane and aids in the ease and effective removal of these diseased structures. The antis inflammatory, anti angiogenic and cell migration inhibition properties of IVTA are of benefit. In the long term macular oedema may recur after months or years.

\section{SUMMARY:}

1. Proliferative Diabetic Retinopathy with vitreous haemorrhage [ADED] is one of the major causes of blindness.

2. Everywhere in the world vitrectomy is the treatment of choice as advocated by Diabetic Retinopathy Vitrectomy Study (DRVS)

3. In India selected centres are offering this treatment.

4. In Kerala the facility for vitrectomy was made available to Regional Institute of Ophthalmology in the year 2005 under National Program for Control of Blindness. [NPCB].

5. During November - December 2005 we conducted a pilot study by giving IVTA to patients with vitreous haemorrhage due to Proliferate Diabetic Retinopathy undergoing vitrectomy. Results of the study were encouraging.

6. Patients with Proliferative Diabetic Retinopathy having high risk characteristics ie; vitreous haemorrhage attending the retina clinic of regional institute of ophthalmology who were found eligible has been recruited for the study.

7. One patient withdrawn from the study at the beginning

8. 79 patients participated in the study

9. They were randomized into 2 groups using simple randomisation procedure.

10. Group 1 patients were subjected to vitrectomy with IVTA.

11. Group 2 patients were subjected to simple vitrectomy

12. Patients in the 2 groups were followed up for a period of 8 weeks.

13. All the79 patients completed the trial.

14. Best corrected visual acuity [BCVA] showed an improvement from the baseline in two groups

15. The IVTA group showed marginal improvement of 3/60 compared to standard treatment group.

16. The intraocular pressure showed an increase in the post surgical period, but it was not clinically significant and not necessitated treatment with IOP lowering drugs.

17. The changes in the lens status in the phakic patients participated in the study were not significantly different in 2 groups to say that IVTA worsens cataract.

18. The clinical trial has shown that there is added benefit in injecting IVTA in patients with proliferative retinopathy with vitreous haemorrhage.

19. The beneficial effect found out in this study is only with a short term follow up of 8 weeks. Longer duration of follow up with larger sample size is necessary to derive conclusive evidences the therapeutic effect.

Limitations of the study 
1. Majority of patients participated in the study had already underwent cataract surgery with intra ocular lens implantation. (40/79 ie 50.63\%), the changes in the lens status of phakic patients were compared in the post surgical period. A large sample size might have been selected for the study to overcome the problem, but due to time constrain I could not do so.

2. Stabilisation of visual acuity occurs usually after 6 months of surgery .So prolonged follow up is necessary to conclude the success of treatment.

3. Changes in the lens status may occur beyond this study period. In this situation also prolonged follow up is necessary.

4. The near vision function of the participants was very poor in the preoperative period and was difficult to quantify, so this was not measured during follow up.

\section{CONCLUSIONS:}

1. Best Corrected Visual Acuity [BCVA] improved following surgery in two groups.

2. The standard treatment group regained BCVA from baseline of to PL+ to $3 / 60$.

3. IVTA group regained BCVA from baseline of PL+TO 6/60 Snellens equivalent.

4. Marginal improvement in the IVTA group is $3 / 60$.

5. As far the patient is concerned 3/60 improvement is useful for daily living activities.

6. There was no clinically significant increase in intraocular pressure in the post surgical period attributable to IVTA.

7. There was no clinically or statistically significant change in the lens status of phakic patients.

8. IVTA in a dose of $0.1 \mathrm{ml}$ [ie; $4 \mathrm{mgm}]$ is safe.

9. The posterior segment findings noted showed no significant difference between 2 groups

10. The beneficial effect found out in this study is only with a short term follow up of 8 weeks.

11. Longer duration of follow up with larger sample size is necessary to derive conclusive evidences of the therapeutic effect.

\section{BIBLIOGRAPHY:}

1. $\quad$ Ryan, Test book of Diseases of the Retina-6th edition; vol; 3.page no 338-339.

2. Clinical ophthalmology - A Systematic Approach -fourth edition; Page no: 454-456

3. Duke -Elders System of ophthalmology 12th edition vol; 16;page no: 412

4. Parsons Disease of the Eye-19th edition, page no:326-329

5. Ryan, Test book of Disease of the Retina -6th edition vol;3,page no :342

6. Wolf-Anatomy of the retina; 4 th edition:652-8

7. Adler's -Ocular physiology; 5th editon:707-81

8. Medical biochemistry Harper.10th edition:584-85

9. The prevalence of diabetic retinopathy among adults-Archives of ophthalmology-2004; 122:552-553.

10. British Journal of ophthalmology 2000 Sep; 8419:1058-60.

11. Clinical ophthalmology -A Systematic Approach -fourth edition: 474.

12. Jonasb. SofnerA-Intraocular injection of cortisones for treatment of diabetic macular oedema, American Journal of Ophthalmology -2001 Sep 132(3):425-7.

13. Matridis $\mathrm{J}$ et al IVTA for refractory diabetic macular oedema, Oph Journal2002 May;109(5):920-7 
14. Pars plana vitrectomy for recalcitrant diabetic macular oedema-Proceedings of All India Ophthalmological society conference 2004;378-

15. IVTA as treatment adjunct to laser photocoagulation in the management of clinically significant macular oedema - Sumith kaushik; AIOC proceedings-2004:351

16. Policy and practice-Blindness prevention -Bulletin of WHO2001:79

17. A RCT comparing IVTA and laser photocoagulation for diabetic macular oedema -Clinical research studies protocol no 05-0107

18. Evaluation of sub retinal triamcinolone toxicity -The journal of Retina vitreous diseases 26 (7) Sep-2006:811-817.

19. IVTA for diabetic macular oedema -Principles and Practice-Vedamtham Vasumathy, Indian Journal Of Ophthalmology vol:54,issue2; 2006:133-7

20. IVTA for diabetic macular oedema -S.A Vernam-British Journal of Ophthalmology 2005; 89:931-933.

21. Sequentially combined vitrectomy -IVTA and macular laser photocoagulation for diabetic macular oedema -Clinical trials. gov; identifier.

22. IVTA for diffuse diabetic macular oedema -Jost B et-al Archives of ophthalmology,2003;121:57-61

23. Ocular morbidity associated with IVTA Doctors guide@eb.doc guide.com 3rd March 2006

24. Retinal physician-Evaluation for diabetic macular oedema treated with IVTA www retinal physician .com-7th March 2006

25. Clinical trial -Efficacy and safety of IVTA-Jose carlose. M.D, Spain.Clincal trial.gov. - 12th March 2006

26. DRVS- Clinical study data base Kupfer.C .ETDRS American journal of ophthalmology.81; 2000:687-690.

27. Jedad, A .Randomized controlled trials. A user's guide. BMJ book shop website - 15th March 2006

28. Pocock, S.J, Randomized clinical trials, British Medical journal 1991

29. Kesavan nair. V.Ghosh C.S M. Phil thesis.

30. Study Implicates a Growth Factor Other than VEGF in Diabetic Retinopathy

31. Source: Watanabe D, Suzuma K, Matsui S, et al. Erythropoietin as a retinal angiogenic factor in proliferative diabetic retinopathy. N Engl J Med 2005;353(8):782-792

32. IVT Clears More Quickly from Vitrectomized Eyes Source: Chin HS, Park, TS, Moon YS, Oh JH.

33. Difference in clearance of intravitreal triamcinolone between vitrectomized and nonvitrectomized eyes. Retina 2005;25(5):556-60

34. Intravitreal triamcinolone option for diabetic macular edema Melvin Dea, MD, PhD did not indicate any financial interest in any aspect of this report. E-mail: dea@usc.edu 4th April 2006

35. The impact of diabetic retinopathy: perspectives from patient focus groups Karin S Coynea, Mary Kay Margolisa, Tessa Kennedy-Martinb, Timothy M Bakera, Ronald Kleinc, Matthew D Pauld and Dennis A Revicki

36. Current Perspectives of Diabetic Retinopathy A Photo-Essay for Health Professionals- John G. O'Shea MD, Robert B. Harvey FRCSE Epidemiology

37. Causes and Treatment of Vitreous Haemorrhage- wwwbjo.com 8th April 2006 
38. Reported symptoms and quality-of-life impacts in patients having laser treatment for sightthreatening diabetic retinopathy. Scanlon, Martin ML, Bailey C, Johnson E, Hykin P, Keightley S. pubmed

39. Intravitreal Triamcinolone (IVT) a leaflet for patients Site updated June 2005

40. The adjunct use of IVTA combined. With pars plana vitrectomy in the form a randomized, double-masked, placebo-controlled trial of intravitreal triamcinolone www.blackwellsynergy.com/doi/pdf/10.1111/j. 16000420.2005.00592 - 12th April 2006

41. Small controlled trials and a large number of cases support the treatment of Charts of patients undergoing combined IVTA and PRP werereviewed.www.noorvision.com/ weblog/archives/ 2005/03/index.ht. - 15th April 2006 